\title{
Phenytoin induced dystonia
}

\author{
Tarık Acar ${ }^{1}$, Gülsüm Alkan², Hüseyin Çaksen², Birsen Ertekin¹, Mehmet Ergin³, Sedat Koçak², \\ Başar Cander ${ }^{3}$ \\ ${ }^{1}$ Department of Emergency Medicine, Beyhekim State Hospital, Departments of ${ }^{2}$ Pediatrics, and ${ }^{3}$ Emergency Medicine, \\ Necmettin Erbakan University Meram Faculty of Medicine, Konya, Turkey. E-mail: biceacil@hotmail.com
}

Received: 17th December 2016, Revised: 17th March 2017, Accepted: 20th March 2017

SUMMARY: Acar T, Alkan G, Çaksen H, Ertekin B, Ergin M, Koçak S, Cander B. Phenytoin induced dystonia. Turk J Pediatr 2018; 60: 111-112.

The abnormalities of dopaminergic activity in the basal ganglia have been emphasized to be effective in dystonia. We hereby report a case of a 2.5-year-old male patient who presented with tonic-clonic sezures and who developed dystonia after being given phenytoin. Biperidene hydrochloride was administered intramuscularly; primidone was added to the treatment regimen. After a 7-day-follow-up at the hospital, the patient had no dystonia and was discharged.

Key words: epilepsy, phenytoin, dystonia.

Although the underlying neuro-chemical pathology is not known, it has been emphasized that abnormalities seen at dopaminergic activity in the basal ganglions are effective in dystonia. It is mostly the side effect of classical antipsychotics; it may also emerge after taking medicines such as metoclopramide, which are effective on the dopaminergic pathway. ${ }^{1}$ The acutely starting extrapyramidal symptoms in childhood are accepted as an urgent medical condition and they need to be alleviated as soon as possible.

Phenytoin, which is a derivative of hydantoin, is widely used in the treatment of tonic-clonic seizure due to its anticonvulsant activity without a sedative effect. In our case, acute dystonia developed approximately 12 hours following phenytoin infusion.

\section{Case Report}

A 2.5-year-old-male patient presented to the hospital with convulsions lasting for approximately 5 minutes and repeating 4-5 times in half an hour. The patient, born through spontaneous vaginal delivery $(2,900 \mathrm{~g})$, had normal development stages. His 11-year-old brother was suffering from epilepsy, diagnosed at the age of four; and was on sodium valproate therapy. Since the patient had an epileptic attack 2 months ago, brain MR was taken to exclude intracranial pathology. Brain MRI of the patient had demonstrated a slight increase at the centrum semioviale level and bilateral forceps major levels in the white matter on T2-weighed images and flair images. It was considered that myelinization had not completed its development in the white matter. As a result of detecting bilateral generalized sharp wave paroxysm in his electroencephalography (EEG), sodium valproate $20 \mathrm{mg}$ was begun.

After 1-month of sodium valproate-treatment, the patient re-presented to the emergency department due to generalized tonic-clonic seizures. Rectal diazepam (10 mg) was administered, which was followed by phenytoin $(20 \mathrm{mg} / \mathrm{kg}$ ). The patient had status epilepticus, and was transferred to the intensive care unit and midazolam infusion was started. Afterwards, the dose of midazolam was tapered gradually as his seizures subsided; an additional dose of phenytoin $(10 \mathrm{mg} / \mathrm{kg}$ ) was administered.

His physical examination revealed: temperature $36.7^{\circ} \mathrm{C}$, blood pressure $95 / 55 \mathrm{~mm} \mathrm{Hg}$, pulse rate $95 / \mathrm{min}$., oxygen saturation $98 \%$; frontal fontanelle was closed, light reaction was positive on both sides with equal sized pupils, and no neck stiffness and pathological reflex. Deep tendon reflexes were normal. Muscle strength was $5 / 5$ for all extremities. Laboratory examination revealed: glucose $90 \mathrm{mg} / \mathrm{dl}$, urea $33 \mathrm{mg} / \mathrm{dl}$, creatinine $0.4 \mathrm{mg} / \mathrm{dl}$, sodium 137 
$\mathrm{mEq} / \mathrm{L}$, potassium $5.1 \mathrm{mEq} / \mathrm{L}$, calcium $10 \mathrm{mg} /$ $\mathrm{dl}$, magnesium $2.4 \mathrm{mg} / \mathrm{dl}$, white blood cell count $12,000 / \mathrm{mm}^{3}$, hemoglobin $12.1 \mathrm{~g} / \mathrm{dl}$, thrombocyte $423,000 / \mathrm{mm}^{3}$. At the 12 th hour of the patient follow-up, dystonic movements involving legs and arms were noticed. Biperidene hydrochloride $(0.04 \mathrm{mg} / \mathrm{kg})$ was administered intramuscularly. At the 10th-15th minute of the follow-up, the dystonic movements disappeared. Since dystonia secondary to phenytoin was considered, phenytoin was discontinued. Primidone $(2.5 \mathrm{mg})$ was added to the treatment. There was bilateral generalized slow wave paroxysm with high amplitude on the control EEG. There were rare bilateral sharp waves and generalized paroxysm appearing at the bilateral front center sides. Seizures and dystonic movements were not observed on the patient-follow-up. After 7-day follow-up at the hospital, the patient was discharged with no dystonia or attacks.

A signed consent was obtained from the parents for publication.

\section{Discussion}

Acute dystonic may develop with metoclopramide, diazepam, chloroquine, phenytoin, carbamazepine, cocaine, codeine along with antihistaminics, expectorants, and decongestants. ${ }^{1}$ If the possibility of acute progressing dystonic reactions connected to the medicine's side effect is not considered, it may be difficult to make an accurate diagnosis. Acute dystonic reaction may often be mistaken with some other illnesses such as meningitis, encephalitis, hypocalcemia and hypomagnesemia, hypoventilation, epilepsy, hysteria, tetanus, insect or scorpion bites. ${ }^{2}$

Dystonia may develop even at therapeutic doses of metoclopramide. Dystonia has been observed to progress after therapeutic doses of phenytoin and carbamazepine. ${ }^{3}$ As a limitation, blood phenytoin level was not measured; so we could not exclude a toxic level of phenytoin. In the treatment of acute dystonia secondary to medicines, general medical care is given; biperidene and sedative medicines are administered for some patients. ${ }^{4}$ It has been reported that only $9.1 \%$ of patients need hospitalization. ${ }^{5}$ Our case was hospitalized, and medicines were used in the same way.

Movement disorders such as asterix, tremor, dyskinesia, dystonia and chorea have been identified after many antiepileptic medications such as barbiturates, carbamazepine, valproate and primidon. ${ }^{6}$ Antiepileptic medications may cause intoxication even at treatment doses due to narrowing of the therapeutic windows. Valproic acid, carbamazepine, phenytoin and phenobarbital intoxications occur very often. Phenytoin is an anticholinergic agent and a central serotonin stimulant. These neurotransmitters may cause movement disorders as a result of having undergone changes in the brain.

A case of limb chorea and dystonia caused by toxic level of phenytoin was reported by Chadwick and his colleagues. ${ }^{7}$ Chalhub et al. ${ }^{8}$ identified the connection between phenytoininduced dystonia with choreoathetosis in two epileptic children.

In conclusion, acute dystonic reaction may develop following phenytoin administration. Acute dystonia is disturbing for both the patients and their families. Physicians should be aware of possible side effects of the drugs and be able to manage acute dystonic reaction properly.

\section{REFERENCES}

1. Uluğ NC, Uluğ M. Acute dystonia due to the use of metoclopramide. Bull Clin Psychopharmacol 2011; 21: 70-72.

2. Campbell D. The management of acute dystonic reactions. Aust Prescr 2001; 24: 19-20.

3. Moss W, Ojukwu C, Chiriboga CA. Phenytoin-induced movement disorder. Unilateral presentation in a child and response to diphenhydramine. Clin Pediatr (Phila). 1994; 33 : 634-638.

4. Balamtekin N, Doksal A, Gülgün M, Vurucu S, Akın R. Olgu sunumu: Acute dystonia due to the use of metoclopramide. Gulhane Medical Journal 2006; 48: 187-188.

5. Cezard C, Nisse P, Quaranta S, Peucelle D, Mathieu-Nolf M. Acute dystonia from metoclopramide in children. Therapie 2003; 58: 367-370.

6. Lacayo A, Mitra N. Report of a case of phenobarbitalinduced dystonia. Clin Pediatr (Phila) 1992; 31: 252.

7. Chadwick D, Reynolds EH, Marsden CD. Anticonvulsantinduced dyskinesias: A comparison with dyskinesias induced by neuroleptics. J Neurol Neurosurg Psychiatry 1976; 39: 1210-1218.

8. Chalhub EG, Devivo DC, Volpe JJ: Phenytoin-induced dystonia and choreoathetosis in two retarded epileptic children. Neurology 1976; 26: 494-498. 